\title{
Antioxidant Sensing of Spiropyrans: Substituent Effects and NMR Spectroscopic Studies
} Joel Garcia,, ${ }^{1,3}$ J. Bennett Addison, ${ }^{4}$ Stephen Z. Liu, ${ }^{1}$ Samuel Lu,5 Andrea L. Faulkner ${ }^{2}$ Blanka M. Hodur, ${ }^{2}$ Edward I. Balmond, ${ }^{6}$ Victor W. Or, ${ }^{1}$ Jason H. Yun, ${ }^{1}$ Kimberly Trevino ${ }^{2}$, Bowen Shen $^{2}$, Jared T. Shaw ${ }^{6}$ Natia L. Frank, ${ }^{5}$ and Angelique Y. Louie ${ }^{1,2,}$,

${ }^{1}$ Department of Biomedical Engineering, University of California, Davis, CA 95616 USA

2 Chemistry Graduate Group, University of California, Davis, CA 95616 USA

3 now at Chemistry Department, De La Salle University, 2401 Taft Avenue, 1004 Manila, Philippines

${ }_{4}^{4}$ Nuclear Magnetic Resonance Facility UC Davis 95616, now at NMR Facility, San Diego State University USA

5 Department of Chemistry, University of Victoria, Victoria, British Columbia V8V 2 Y2 Canada

${ }^{6}$ Department of Chemistry, University of California, Davis, CA 95616 USA

E-mail: aylouie@ucdavis.edu

$\begin{array}{ll}\text { Page } & \text { Contents } \\ \text { S1 } & \text { Table of Contents } \\ \text { S2 } & \text { Figure S-1 } \\ \text { S3 } & \text { Figures S-2 } \\ \text { S4 } & \text { Table S-1 } \\ \text { S5 } & \text { Figure S-3 } \\ \text { S6 } & \text { Figure S-4 } \\ \text { S7 } & \text { Figure S-5 } \\ \text { S8 } & \text { Figure S-6 } \\ \text { S9 } & \text { Table S-2 } \\ \text { S10 } & \text { Figure S-7 } \\ \text { S11 } & \text { Derivation of the Working Equation for Rate } \\ & \text { Constant Determination } \\ \text { S13 } & \text { Thermal Relaxation of SP-1, 3, 7, and 9 } \\ \text { S36 } & \text { References }\end{array}$


(A)

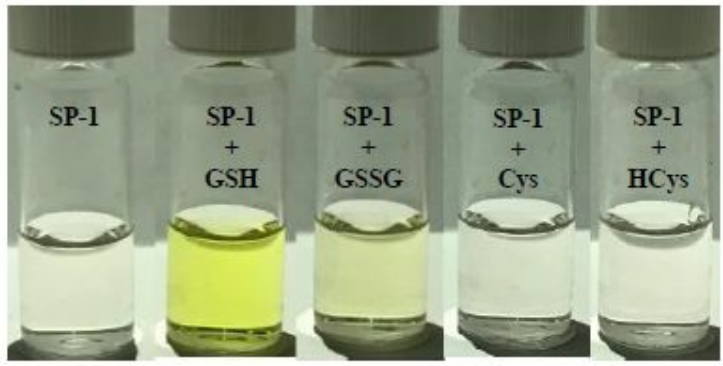

(C)

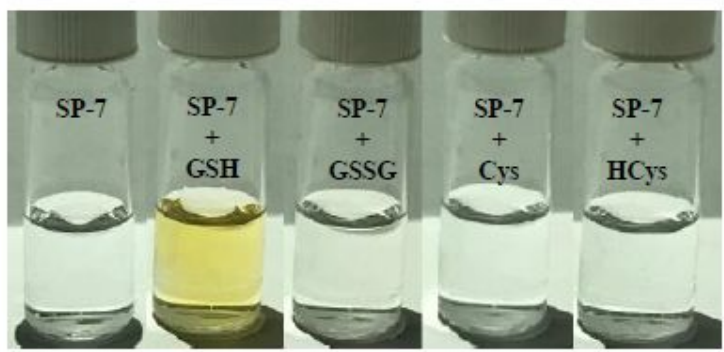

(B)

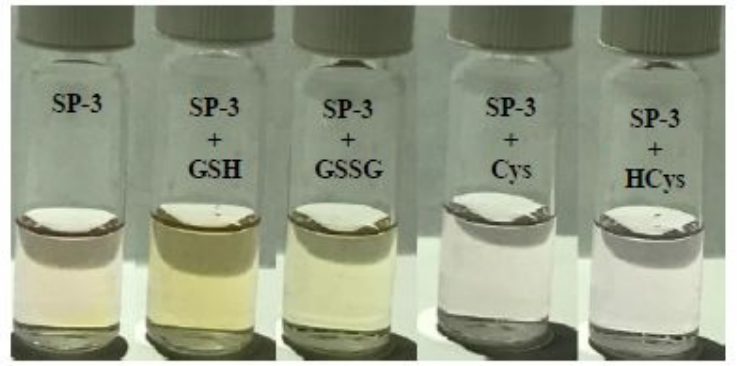

(D)

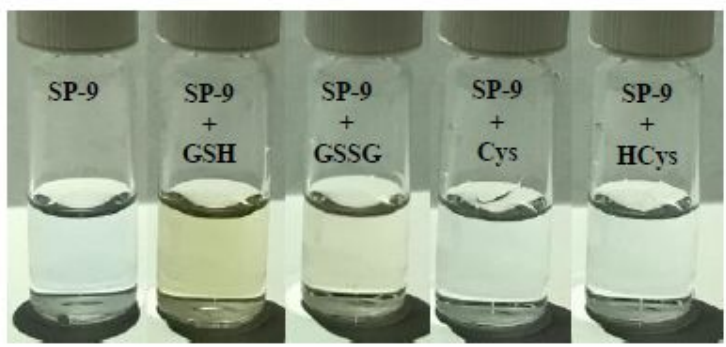

Figure S-1. Color change, or lack thereof, of $0.1 \mathrm{mM}$ spiropyrans (A) SP-1, (B) SP-3, (C) SP-7, and (D) SP-9 upon addition of equimolar GSH, GSSG, Cys, or HCys. 

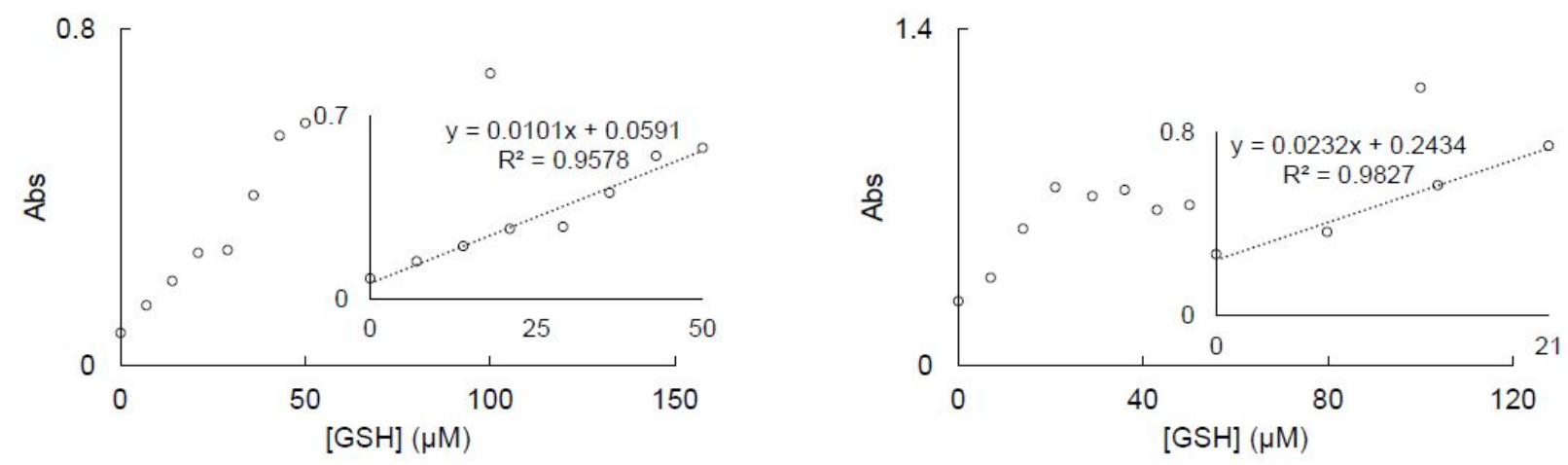

Figure S-2. Plot of merocyanine absorbance of spiropyrans SP-7 (left) and SP-9 (right) with different GSH levels in 50\% ethanol in water. Inset shows the linearity of response for both spiropyrans from 0 to $50 \mu \mathrm{M}$ and from 0 to $20 \mu \mathrm{M}$ for $\mathbf{S P - 7}$ and SP-9, respectively. Samples were incubated in the dark for 3 min prior to absorbance measurements. 
Table S-1. Merocyanine absorption data of $0.05 \mathrm{mM}$ spiropyrans SP-1, 3, 7, and 9 at different GSH levels in 50\% ethanol in water ( $\mathrm{pH} 7.4)$ at ambient temperature. Absorbance measurements were done in triplicates.

\begin{tabular}{llllll}
\hline [GSH], & equiv & \multicolumn{5}{l}{ Merocyanine Absorbance } \\
\cline { 3 - 6 }$\mu \mathrm{M}$ & GSH & SP-1 & SP-3 & SP-7 & SP-9 \\
\hline 21 & 0.42 & 0.208 & 0.626 & 0.315 & 0.591 \\
& & 0.197 & 0.582 & 0.284 & 0.739 \\
7 & & 0.213 & 0.509 & 0.326 & 0.664 \\
& 0.14 & 0.177 & 0.440 & 0.130 & 0.384 \\
& & 0.180 & 0.437 & 0.122 & 0.374 \\
4 & 0.08 & 0.162 & 0.453 & 0.165 & 0.404 \\
& & 0.143 & 0.453 & 0.103 & 0.344 \\
& & 0.118 & 0.436 & 0.0784 & 0.338 \\
& & & & 0.105 & 0.324 \\
\hline
\end{tabular}



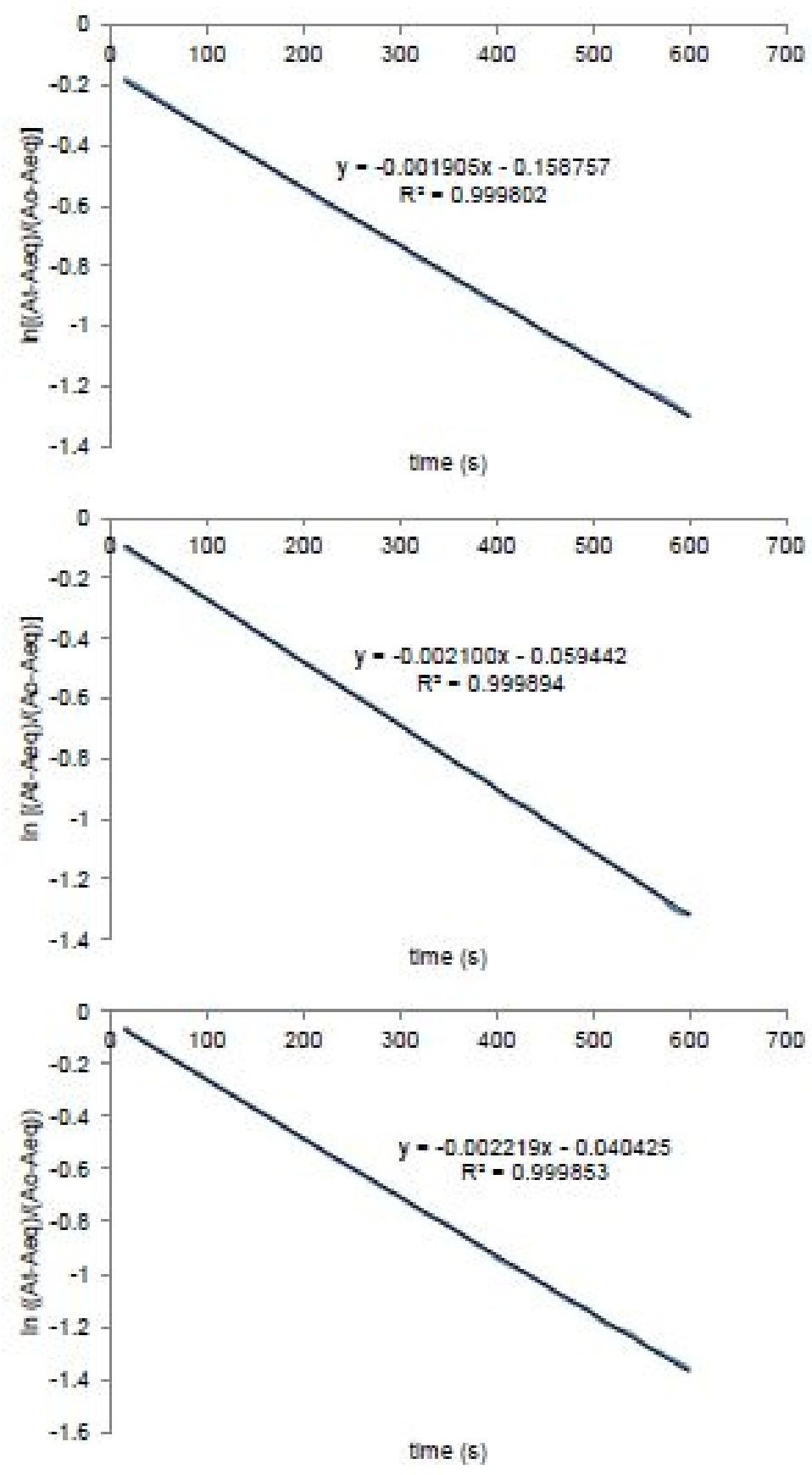

Figure S-3. Kinetic plots (three trials) of $0.05 \mathrm{mM} \mathrm{SP-1}$ in the presence of 20 equiv GSH in 50\% ethanol in water ( $\mathrm{pH} 7.4)$. 

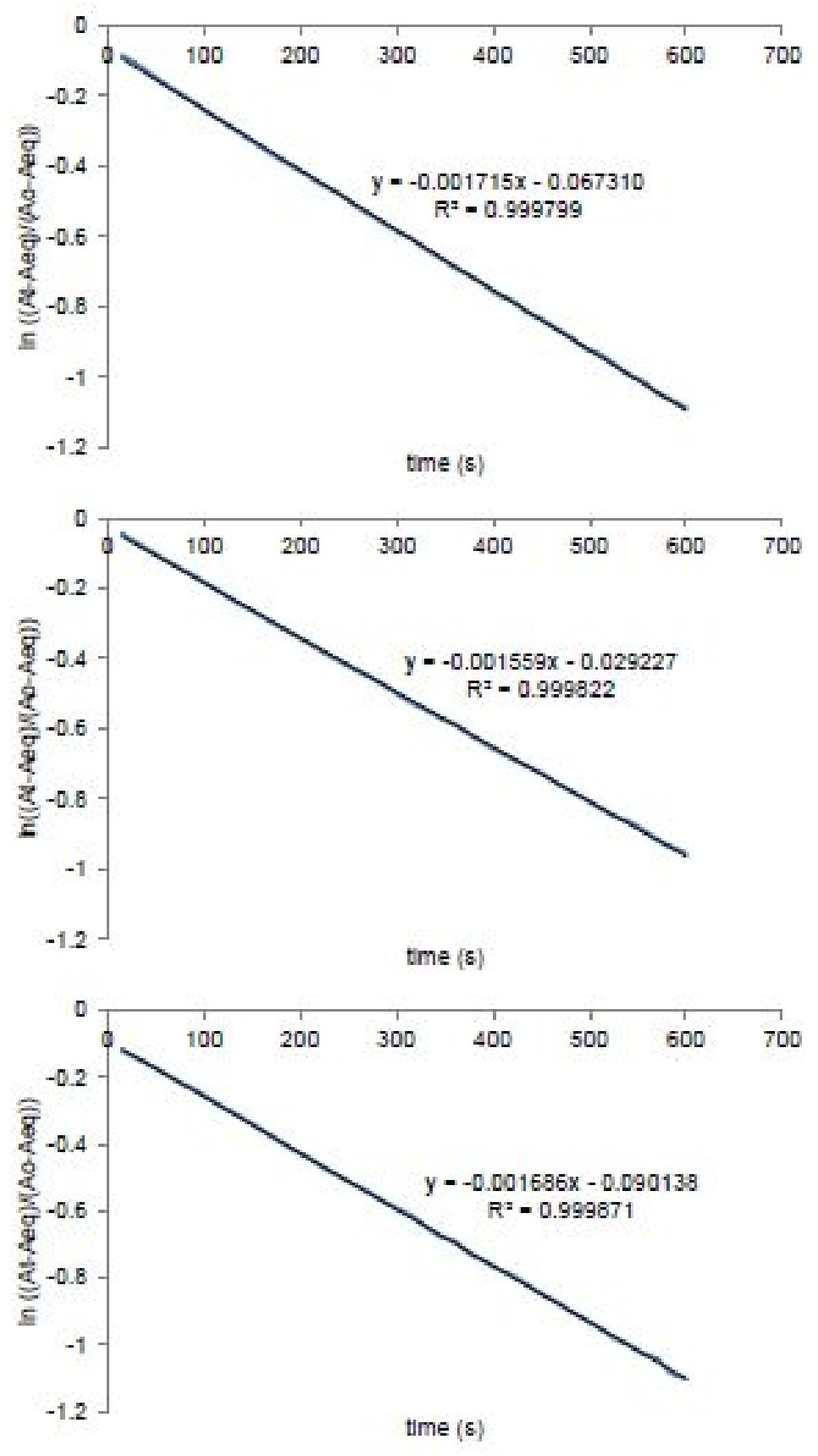

Figure S-4. Kinetic plots (three trials) of $0.05 \mathrm{mM} \mathrm{SP-3}$ in the presence of 20 equiv GSH in 50\% ethanol in water ( $\mathrm{pH}$ 7.4). Kinetic measurements were done in triplicates. 

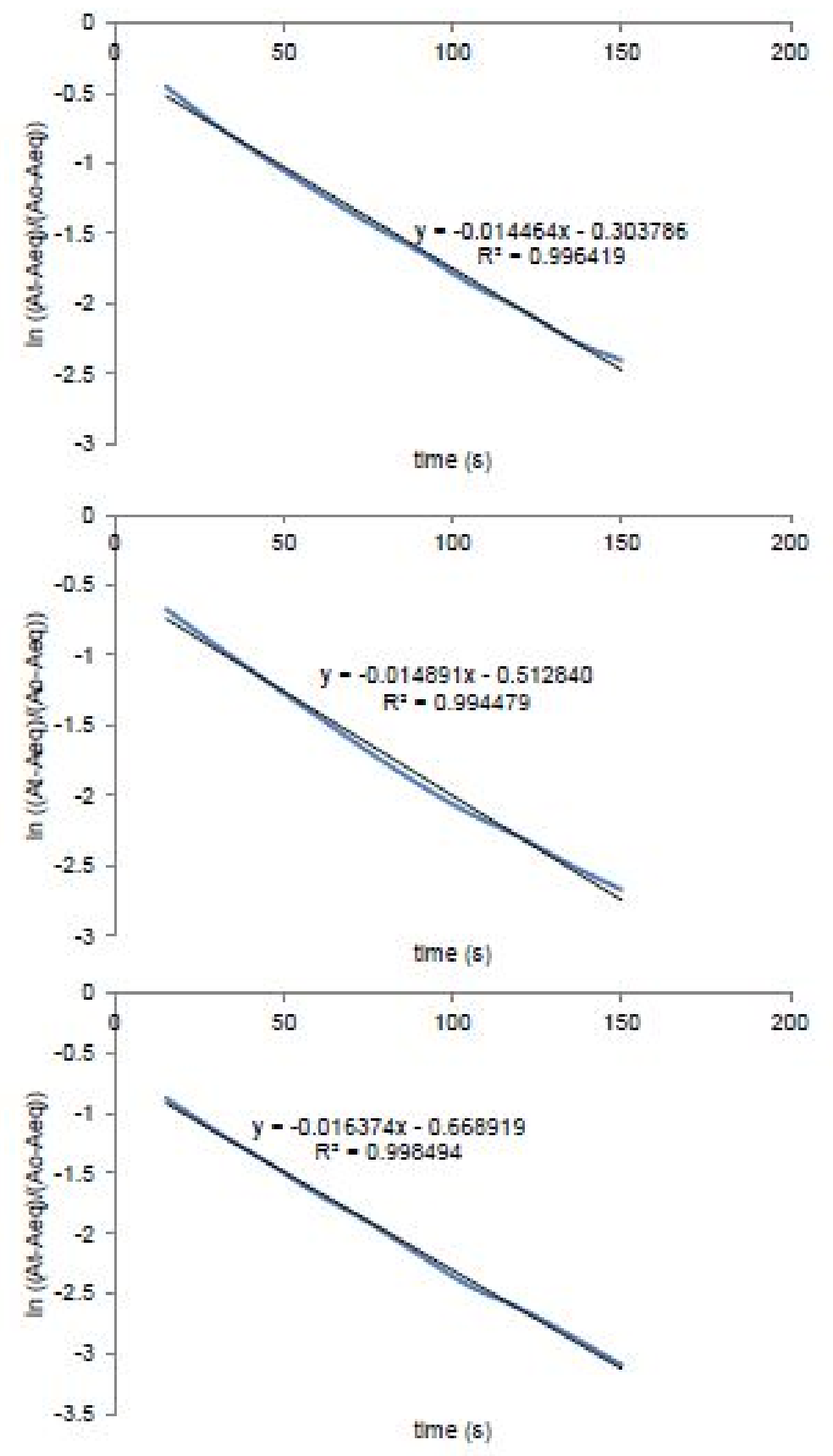

Figure S-5. Kinetic plots (three trials) of $0.05 \mathrm{mM} \mathrm{SP-7}$ in the presence of 20 equiv GSH in 50\% ethanol in water ( $\mathrm{pH}$ 7.4). Kinetic measurements were done in triplicates. 


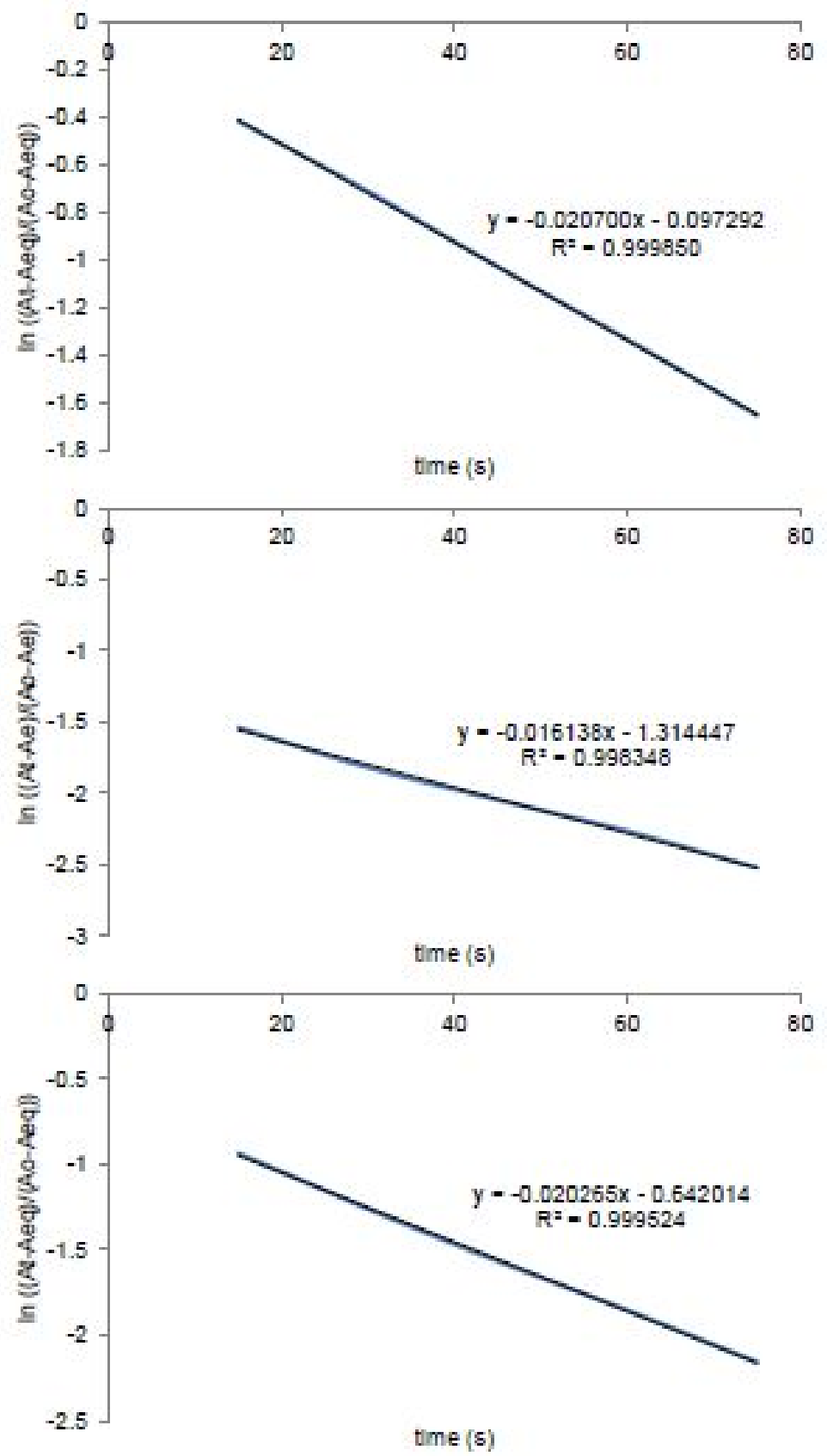

Figure S-6. Kinetic plots (three trials) of $0.05 \mathrm{mM} \mathrm{SP-9}$ in the presence of 20 equiv GSH in 50\% ethanol in water ( $\mathrm{pH} 7.4)$. Kinetic measurements were done in triplicates. 
Table S-2. ${ }^{1} \mathrm{H}$ and ${ }^{13} \mathrm{C}$ NMR chemical shifts of the closed SP-9 and open MC-9 forms in 1:1 acetonitrile-d3/PBS- $\mathrm{H}_{2} \mathrm{O}(\mathrm{pH} 7.4)$, and changes in chemical shift as a result of incubation in the dark (self-induced ring opening) and introduction of GSH (GSH-induced ring opening).

\begin{tabular}{|c|c|c|c|c|c|c|c|c|c|}
\hline \multirow{3}{*}{$\begin{array}{l}\text { Atom } \\
\text { Number }\end{array}$} & \multicolumn{6}{|c|}{ Chemical Shift (ppm) } & \multicolumn{3}{|c|}{ Chemical Shift Changes (ppm) } \\
\hline & \multicolumn{2}{|c|}{$\begin{array}{l}\text { SP-9 } \\
\text { (closed) }\end{array}$} & \multicolumn{2}{|c|}{$\begin{array}{l}\text { MC-9 } \\
\text { (self-induced) }\end{array}$} & \multicolumn{2}{|c|}{$\begin{array}{c}\text { MC-9 } \\
\text { (GSH-induced) }\end{array}$} & \multicolumn{2}{|c|}{$\begin{array}{l}\Delta \sigma \text { due to } \\
\text { ring-opening }\end{array}$} & \multirow{2}{*}{$\begin{array}{c}\Delta \sigma \text { due to } \\
\text { GSH } \\
\text { interaction }\end{array}$} \\
\hline & ${ }^{1} \mathrm{H}$ & ${ }^{13} \mathrm{C}$ & ${ }^{1} \mathrm{H}$ & ${ }^{13} \mathrm{C}$ & ${ }^{1} \mathrm{H}$ & ${ }^{13} \mathrm{C}$ & ${ }^{1} \mathrm{H}$ & ${ }^{13} \mathrm{C}$ & \\
\hline 2 & 6.67 & 112.67 & 7.07 & NA & 7.10 & 115.88 & 0.40 & 3.21 & 0.03 \\
\hline 3 & 6.47 & 115.78 & 7.51 & NA & 7.57 & 116.76 & 1.04 & 0.98 & 0.06 \\
\hline 6 & 6.71 & 110.33 & 7.20 & NA & 7.23 & 109.28 & 0.49 & -1.05 & 0.03 \\
\hline 10 & 5.71 & 120.99 & 7.33 & NA & 7.43 & 112.68 & 1.62 & -8.31 & 0.10 \\
\hline 11 & 6.84 & 130.06 & 8.40 & NA & 8.38 & 148.31 & 1.56 & 18.25 & -0.02 \\
\hline 14 & 6.42 & 108.36 & 6.82 & NA & 6.93 & 118.98 & 0.40 & 10.62 & 0.11 \\
\hline 15 & 6.64 & 116.22 & 7.02 & NA & 7.04 & 123.78 & 0.38 & 7.56 & 0.02 \\
\hline 17 & 6.69 & 112.58 & 7.21 & NA & 7.30 & 112.83 & 0.52 & 0.25 & 0.09 \\
\hline 19 & 1.16 & 20.13 & 1.68 & NA & 1.69 & 26.63 & 0.52 & 6.50 & 0.01 \\
\hline 20 & 1.06 & 25.78 & 1.68 & NA & 1.69 & 26.63 & 0.62 & 0.85 & 0.01 \\
\hline 21 & 2.55 & 29.59 & 3.86 & NA & 3.92 & 34.89 & 1.31 & 5.30 & 0.06 \\
\hline 23 & 3.68 & 56.61 & 3.83 & NA & 3.84 & 56.95 & 0.15 & 0.34 & 0.01 \\
\hline 25 & 3.66 & 56.45 & 3.75 & NA & 3.77 & 56.62 & 0.09 & 0.17 & 0.02 \\
\hline
\end{tabular}

Legend: $\quad \mathrm{NA}$ - not applicable 
SP-2 1 M l h

\section{SP-4}

Wh hu

\section{SP-5}

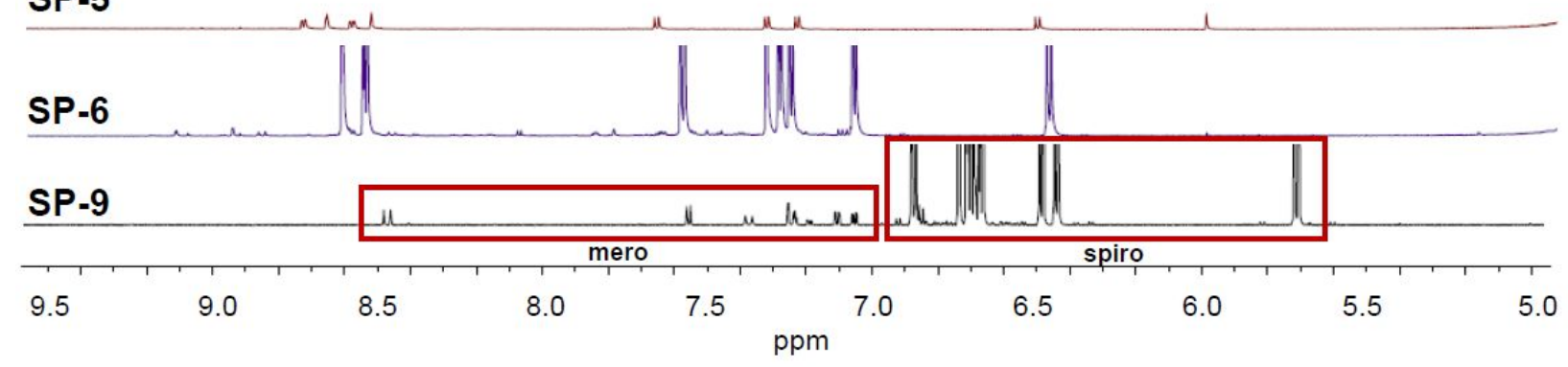

Figure S-7. ${ }^{1} \mathrm{H}$ NMR spectrum showing the aromatic and olefinic proton resonances of spiropyrans SP-2, 4, 5, 6, and 9 in the absence of GSH. Proton resonances of spiropyrans that are not responsive to GSH (SP-2, 4, 5, and 6) are found in more downfield region, similar to where the mero resonances of the GSH-responsive spiropyran (SP-9) are found, indicating that these nonresponsive spiropyrans are already present in their ring-open mero form. 


\section{Derivation of the Working Equation for Rate Constant Determination}

A simple reversible first-order reaction model can be expressed as:

$$
\mathrm{A} \underset{k_{r}}{\stackrel{k_{f}}{\rightleftharpoons}} \mathrm{B}
$$

\section{Scheme 1}

If $[A]_{0}=[A]+[B]$ are initial boundary conditions, the rate equation for the reaction can be written as:

$$
\begin{aligned}
\frac{d[B]}{d t}= & k_{f}[A]-k_{r}[B] \\
& =\left(-k_{f}-k_{r}\right)[B]+k_{f}[A]_{0}
\end{aligned}
$$

where $[\mathrm{A}]_{0}$ is the initial concentration of $\mathrm{A},[\mathrm{B}]$ is the concentration of $\mathrm{B}$, and $[\mathrm{A}]$ is the concentration of $\mathrm{A}$ at any time $t$. At equilibrium conditions, rate of forward reaction equals rate of backward reaction, hence, $k_{f}[\mathrm{~A}]=k_{r}[\mathrm{~B}]$. Also, $[\mathrm{A}]$ and $[\mathrm{B}]$ become $[\mathrm{A}]_{\mathrm{eq}}$ and $[\mathrm{B}]_{\mathrm{eq}}$, respectively.

$$
\frac{k_{f}}{k_{r}}=\frac{[B]_{e q}}{[A]_{e q}}=K=\text { equilibrium constant }
$$

At equilibrium, the initial boundary condition as described by the equation $[\mathrm{A}]_{0}=[\mathrm{A}]+[\mathrm{B}]$ would become $[\mathrm{A}]_{0}=[\mathrm{A}]_{\mathrm{eq}}+[\mathrm{B}]_{\mathrm{eq}}$. Upon rearrangement,

$$
[\mathrm{A}]_{\mathrm{eq}}=[\mathrm{A}]_{0}-[\mathrm{B}]_{\mathrm{eq}}
$$

Substituting $[\mathrm{A}]_{\mathrm{eq}}$ expression described in (3) to that in (2),

$$
\begin{aligned}
& K=\frac{[B]_{e q}}{[A]_{e q}}=\frac{k_{f}}{k_{r}}=\frac{[B]_{e q}}{[A]_{0}-[B]_{e q}}, \text { which can be rearranged to make } \\
& {[B]_{e q}=\frac{K[A]_{0}}{1+K}=\frac{k_{f}[A]_{0}}{k_{f}+k_{r}}}
\end{aligned}
$$

Therefore,

$$
\begin{aligned}
\frac{d[B]}{d t} & =\left(-k_{f}-k_{r}\right)[B]+k_{f}\left[\frac{\left(k_{f}+k_{r}\right)[B]_{e q}}{k_{f}}\right] \\
& =-\left(k_{f}+k_{r}\right)\left([B]-[B]_{e q}\right)
\end{aligned}
$$

Upon rearrangement,

$$
\frac{d[B]}{[B]-[B]_{e q}}=-\left(k_{f}+k_{r}\right) d t
$$

Upon integration, 
Garcia et. al.

$$
\begin{aligned}
& \int_{[B]_{0}}^{[B]} \frac{d[B]}{[B]-[B]_{e q}}=\int_{0}^{t}-\left(k_{f}+k_{r}\right) d t \\
& {[B]-[B]_{e q}=\left([B]_{0}-[B]_{e q}\right) e^{-\left(k_{f}+k_{r}\right)^{t}}}
\end{aligned}
$$

The linear form of the above equation (7) can be expressed as:

$$
\ln \left(\frac{[B]-[B]_{e q}}{[B]_{0}-[B]_{e q}}\right)=-\left(k_{f}+k_{r}\right) t
$$

In the case of spiropyran isomerizing to merocyanine in the presence of glutathione (GSH), excess GSH (20 equivalent) can be used make the isomerization process follow a pseudo-first-order reaction and obey the above linear expression (8).

Because merocyanine is the visible-light-absorbing species, not spiropyran, then the merocyanine absorbance can be substituted for the merocyanine concentration in equation (8). The working equation for the determination of the observed rate constant would be:

$$
\ln \left(\frac{A-A_{e q}}{A_{0}-A_{e q}}\right)=-\left(k_{f}+k_{r}\right) t
$$

where $A$ is the absorbance of the GSH-containing spiropyran solution at any time $t, A_{e q}$ is the absorbance of the solution at equilibrium, and $A_{0}$ is the absorbance of the solution at $t=0$. 


\section{Thermal Relaxation of GSH-Responsive Spiropyrans}

\section{Spiropyran SP-1}

The absorbance spectra of SP1 revealed a weak absorption at $550 \mathrm{~nm}$ due to the merocyanine being present in low concentrations as well as an additional absorbance band at 400 $\mathrm{nm}$. Irradiation of the MC form with $550 \mathrm{~nm}$ light led to a decrease in intensity of both the $550 \mathrm{~nm}$ and $400 \mathrm{~nm}$ wavelengths. The relative intensity of the $400 \mathrm{~nm}$ and $550 \mathrm{~nm}$ bands were measured as a function of spiropyran and water concentration in absolute ethanol (100\%). The increasing ratio of water volume relative to ethanol volume in the sample are: $1 / 60(1.6 \% \mathrm{v} / \mathrm{v}), 1 / 30(3 \% \mathrm{v} / \mathrm{v})$ , $1 / 15(7 \% \mathrm{v} / \mathrm{v})$. With the addition of water, the relative intensities of the $400 / 550 \mathrm{~nm}$ ratio were $0.053: 0.097(0.55), 0.104: 0.139(0.75)$ and $0.135: 0.168(0.80)$. This suggests the mole fraction of each species absorbing at 400 and 550 to be water dependent and, therefore, not due to the same species. If the absorbances at 400 and 550 were due to the same species, then an isosbestic point should be observed in the irradiation/thermal cycling experiments. Close inspection of the absorption spectra reveals two minor crossings, but no clear isosbestic point consistent with multiple species in solution. It is therefore proposed that the species at 400 and $550 \mathrm{~nm}$ are two different species, with the species absorbing at $550 \mathrm{~nm}$ being the typical monomeric $\mathrm{MC}$ form and the species absorbing at $400 \mathrm{~nm}$ being an aggregate.

Both the $400 \mathrm{~nm}$ species and $550 \mathrm{~nm}$ species respond to visible irradiation, but with differing thermal relaxation kinetics. Compound $\mathrm{X}$ increases in concentration with increasing water concentration, is light-responsive, and has slower relaxation kinetics $\left(0.08 \mathrm{~s}^{-1}\right) \mathrm{vs}$ the species (MC) absorbing at $550 \mathrm{~nm}\left(0.12 \mathrm{~s}^{-1}\right)$. The first run and second run of following thermal relaxation at $550 \mathrm{~nm}$, the normal absorption band of merocyanines, led to thermal relaxation values of 1.22 $\mathrm{x} 10^{-2} \mathrm{~s}^{-1}$, and $1.38 \times 10^{-1} \mathrm{~s}^{-1}(0.12$ and 0.14$)$, which are the same within experimental error. The 
thermal relaxation followed at $400 \mathrm{~nm}$, however, leads to an average rate constant of $8.39 \times 10^{-2}$ $\mathrm{s}^{-1},(0.08)$ which is slower by more than the deviation of $0.02 \mathrm{~s}^{-1}$, suggesting that the species absorbing at $400 \mathrm{~nm}$ is indeed a distinct form with slower relaxation kinetics. 

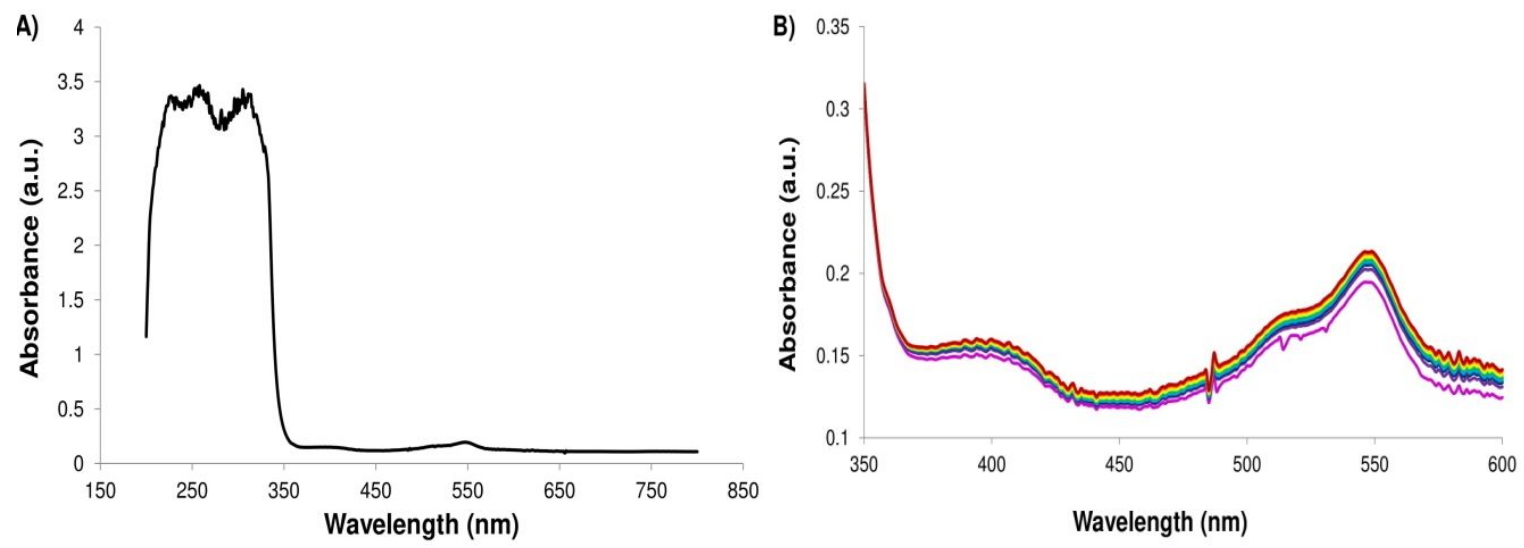

Figure S-8. (a) Initial electronic absorption spectrum of SP1 in ethanol $\left(7.13 \times 10^{-3} \mathrm{M}\right)$ at $300 \mathrm{~K}$ in the dark adapted state. (b) Increase of PMC $\pi-\pi^{*}$ transition with increasing population of the PMC state due to thermal relaxation following formation of a photostationary state by visible irradiation. 


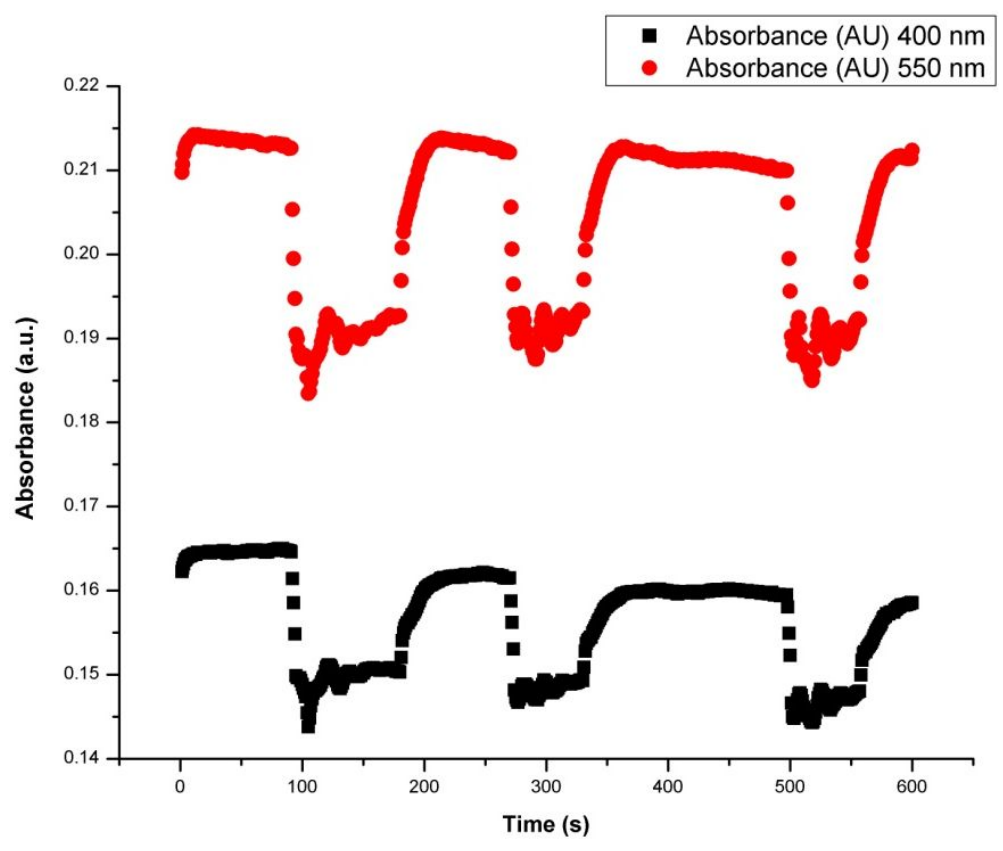

Figure S-9. Absorbance $(\bullet)$ at $400 \mathrm{~nm}$ and (ש) at $550 \mathrm{~nm}$ of SP1 in ethanol $\left(7.13 \times 10^{-3} \mathrm{M}\right)$ as a function of time upon thermal relaxation/visible irradiation. (a) 0-90 s dark, (b) $90 \mathrm{~s}$ light on, resulting in a decrease in absorbance at $550 \mathrm{~nm}$ due to ring closure, (c) at 180s, dark cycle, allowing thermal relaxation back to the open form. The light and dark cycles were carried out by light excitation followed by a dark cycle with an overall duration of $600 \mathrm{sec}$, data collection at $1 \mathrm{sec}$ intervals, at $300 \mathrm{~K}$. 


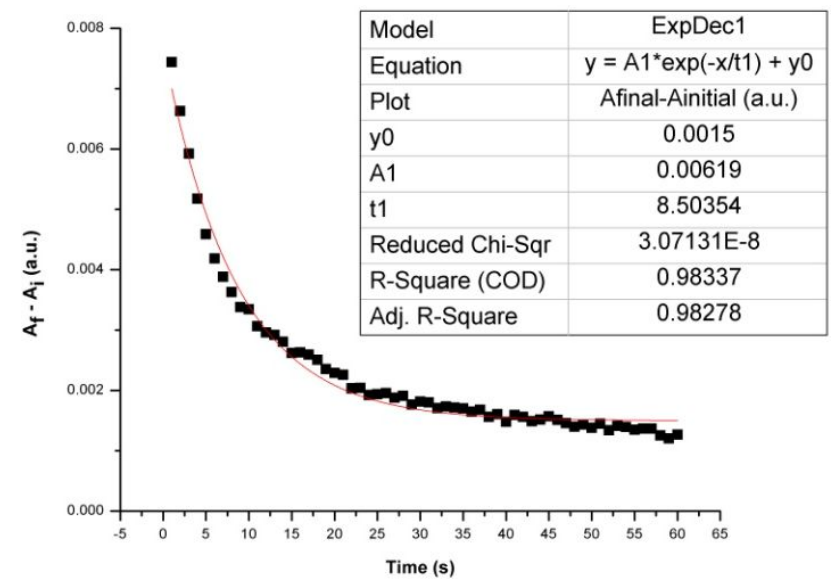

Figure S-10. Representative first order monoexponential fit (-) at $550 \mathrm{~nm}$ for SP1, upon thermal relaxation after generating a photostationary state with visible light irradiation. Average rate of three runs at $550 \mathrm{~nm}=1.22 \times 10^{-1} \mathrm{~s}^{-1}\left(0.12 \mathrm{~s}^{-1}\right)$. (In this equation, $\mathrm{x}$ is the time $(\mathrm{x}$-axis), and $1 / \mathrm{t} 1=$ $\mathrm{k}$, the rate.) 


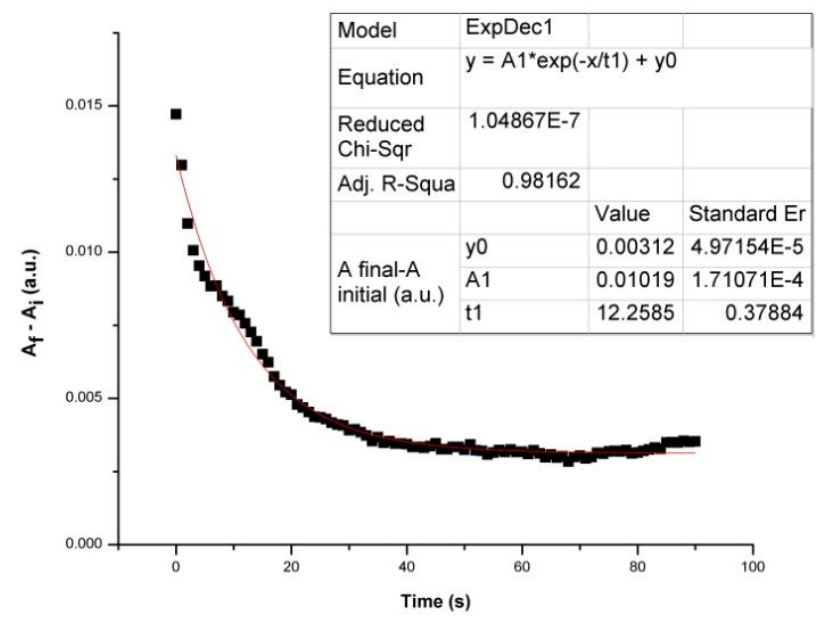

Figure S-11. Representative first order monoexponential fit (-) of the Absorbance $_{\text {final }}$ Absorbance $_{\text {initial }}(\mathbf{\square})$ at $400 \mathrm{~nm}$ for SP1, upon thermal relaxation after generating a photostationary state with $100 \mathrm{~mW}$ visible light irradiation $\left(k=8.15 \times 10^{-2} \mathrm{~s}^{-1}\right)$. Average rate over multiple runs at $400 \mathrm{~nm}=8.39 \times 10^{-2} \mathrm{~s}^{-1}$. 


\section{Spiropyran SP-3}

The behaviour of SP3 was quite typical of spiropyrans, in which the ground state is the closed SP form with a small amount of open form present in solution at room temperature due to the presence of a thermal equilibrium between the two forms. The initial spectrum of SP3 (Fig. 6) revealed that the PMC form to exhibit a broad absorbance band at ( $\left.\lambda_{\max } 575 \mathrm{~nm}\right)$ in the visible; this is typical of the open-form of spiropyrans. The ring closure and opening kinetics revealed first order behaviour (Fig.7), although the fluctuation of the absorbance with irradiation time suggest the possibility of photothermal effects. The thermal relaxation kinetics (Fig. 8) were found to be strictly first order with a rate of $1.83 \pm 0.02 \times 10^{-1} \mathrm{~s}^{-1}$ for SP3. 

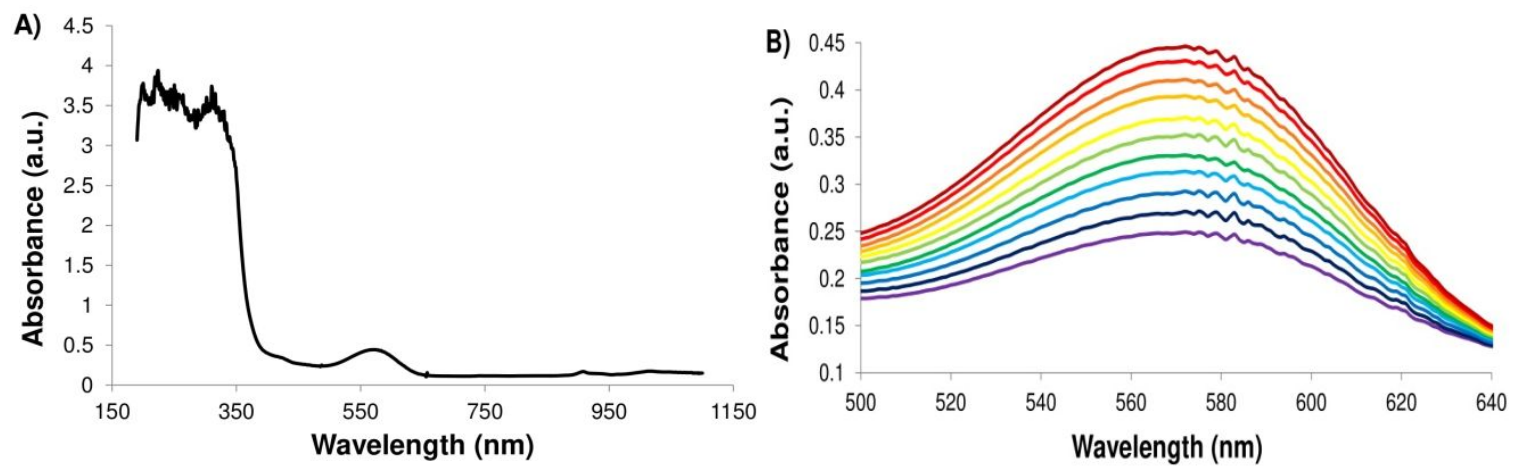

Figure 12. (a) Initial electronic absorption spectrum of SP3 in ethanol $\left(1.12 \times 10^{-2} \mathrm{M}\right)$ at $300 \mathrm{~K}$ in the absence of ambient light. (b) Increase of PMC $\pi-\pi^{*}$ transition with increasing population of the PMC form due to thermal relaxation after formation of a visible-light induced photostationary state. 


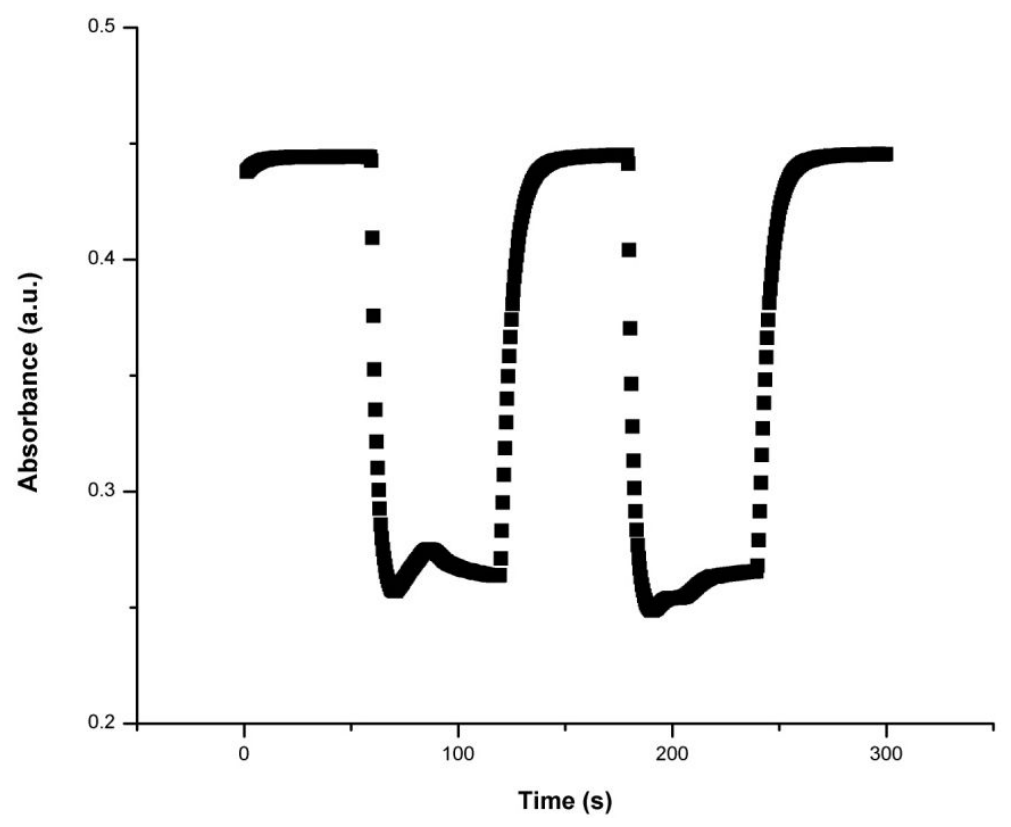

Figure S-13. Absorbance ( $\mathbf{a})$ at $575 \mathrm{~nm}$ of SP3 in ethanol $\left(1.12 \times 10^{-2} \mathrm{M}\right)$ as a function of time upon thermal relaxation/visible irradiation. Light and dark cycles were carried out by thermal data collection for $60 \mathrm{~s}$, followed by excitation for $60 \mathrm{~s}$ and dark cycle for $60 \mathrm{~s}$ with an overall duration of light/dark cycles of $300 \mathrm{~s}$, data collection at $0.5 \mathrm{sec}$ interval, at $300 \mathrm{~K}$. 


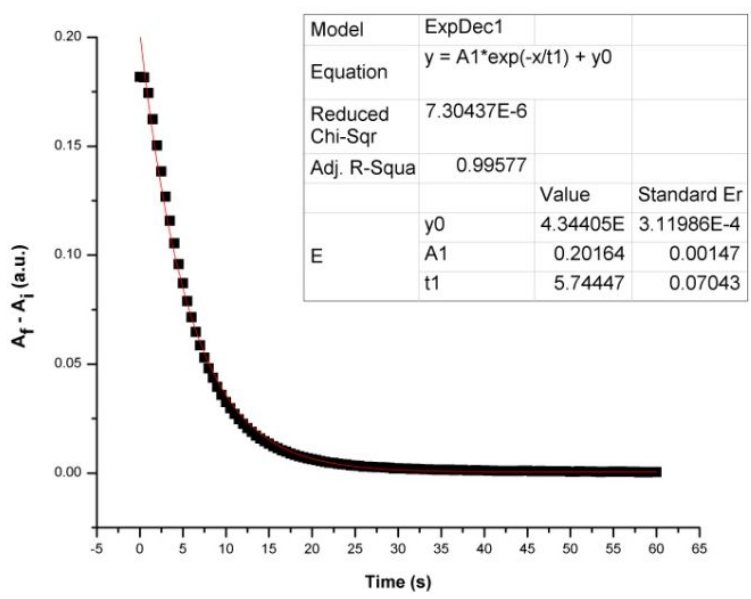

Figure S-14. First order monoexponential fit (-) of the first cycle (left), and second cycle (right). Absorbance final $_{-}-$Absorbance $_{\text {initial }}(\mathbf{\square})$ at $575 \mathrm{~nm}$ for SP3, upon thermal relaxation after generating a photostationary state with $100 \mathrm{~mW}$ of visible radiation. Relaxation rate average $=$ $1.83 \times 10^{-1} \mathrm{~s}^{-1}$. 


\section{Spiropyran 7}

The initial spectrum of SP7 (Fig 9) showed a more narrow band ( $\lambda_{\max } 545 \mathrm{~nm}$ ) with perhaps vibronic structure $\left(\lambda_{\max } 515 \mathrm{~nm}\right)$ that is typical of the MC form of spiropyrans. There is, however. a broad band underneath this with a shoulder at $600-650 \mathrm{~nm}$ that may be due to the presence of other species in solution and is atypical of the electronic absorption spectra of spiropyrans. In the first irradiation/thermal relaxation cycle, in the absence of irradiation $\left(t_{0}\right)$, a small increase in absorbance at $515 \mathrm{~nm}$ was observed. This is perhaps due to equilibration in solution towards the open-form or the generation of a secondary species that absorbs in this region. With irradiation, a small decrease in the absorbance at 515 and $545 \mathrm{~nm}$ was observed (Fig 10) that is consistent with the ring-closure processes. The behaviour is non-monotonic, suggesting that photothermal effects and perhaps degradation takes place. In the absence of irradiation, thermal relaxation back to the open form takes place (Fig 11), as evidenced by a rapid rise phase due to thermal relaxation. There is also a slow rise phase, perhaps due to a secondary thermal process or formation of a secondary species in solution, consistent with the long wavelength absorption band (600-650 nm). Two exponential rates were fit to the cycle data for SP7, an initial short fast phase lasting 10 seconds (Fig 12), with a rate of $6.99 \times 10^{-1} \mathrm{~s}^{-1}\left(\sim 0.7 \mathrm{~s}^{-1}\right.$, close to the thermal relaxation rate for SP3). At longer timescales, a long and slow relaxation process is observed (Fig 13) that was fit to a monoexponential process with a rate of $1.94 \times 10^{-2} \mathrm{~s}^{-1}\left(\sim 0.02 \mathrm{~s}^{-1}\right)$. This is an order of magnitude slower than the initial, fast process. The fast process is attributed to thermal relaxation to the open form, while the second long slow phase is associated with a secondary species/process in solution, perhaps associated with the species that absorbs around $600 \mathrm{~nm}$. 

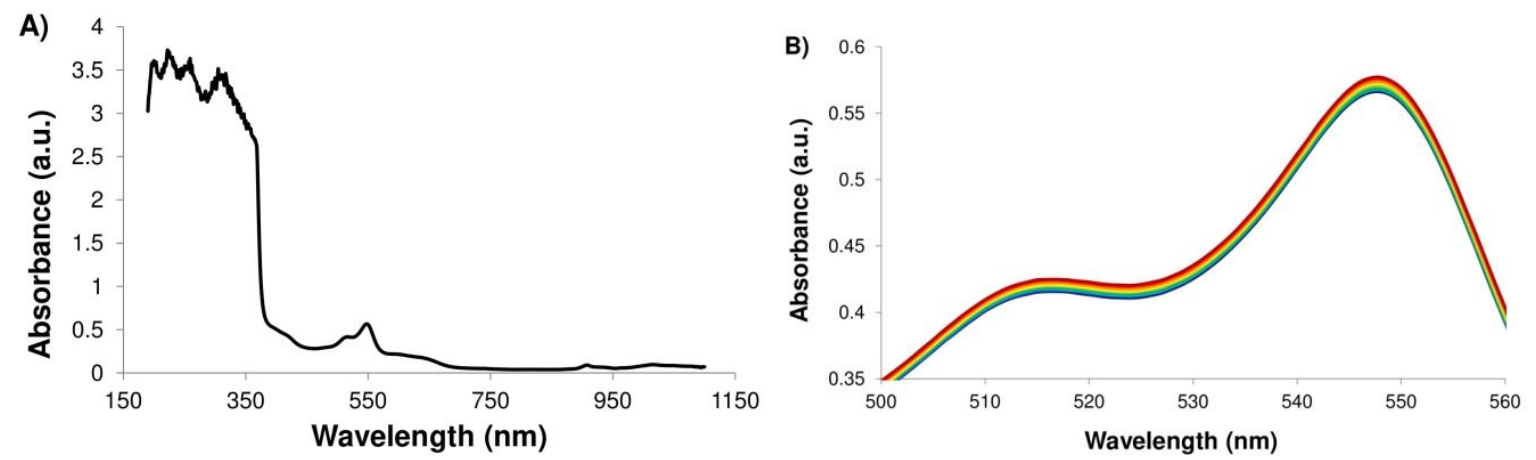

Figure S-14. (a) Initial electronic absorption spectrum of SP7 in ethanol $\left(3.65 \times 10^{-2} \mathrm{M}\right)$ at $300 \mathrm{~K}$ in the absence of ambient light. (b) Increase of PMC $\pi-\pi^{*}$ transition with increasing population of the PMC state due to thermal relaxation following formation of a photostationary state with visible irradiation. 


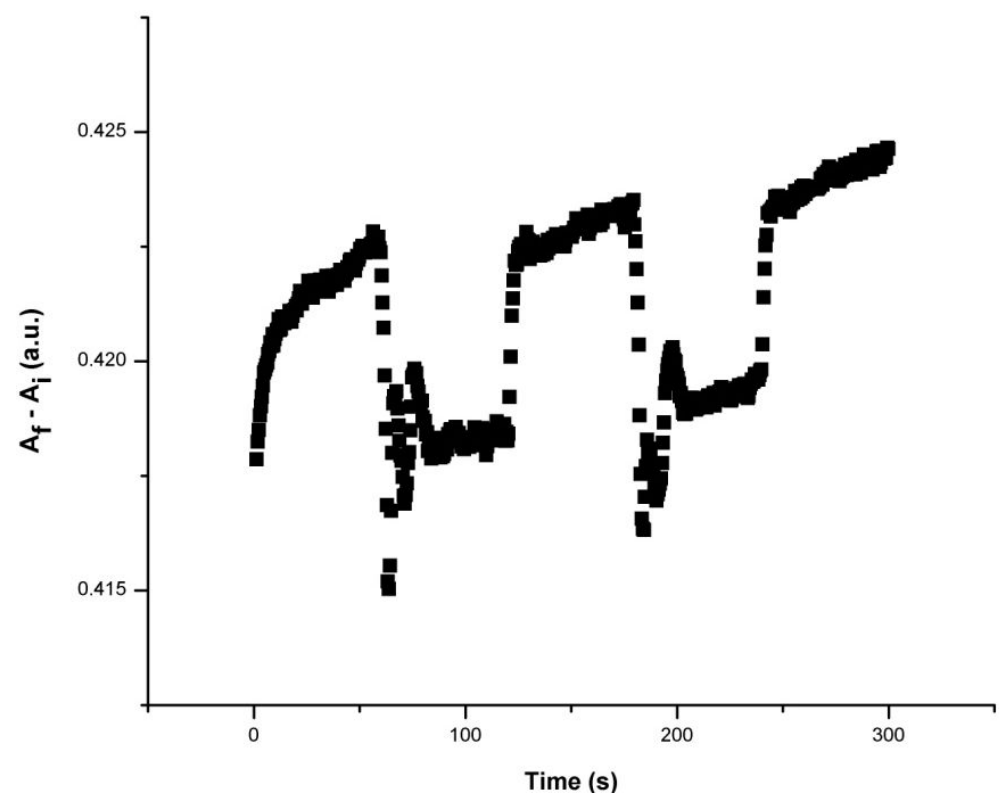

Figure S-15. Absorbance ( $\mathbf{a})$ at $515 \mathrm{~nm}$ of SP7 in ethanol $\left(3.65 \times 10^{-2} \mathrm{M}\right)$ as a function of time upon thermal relaxation/visible irradiation cycles. Light and dark cycles were carried out by thermal data collection for $60 \mathrm{~s}$, followed by excitation for $60 \mathrm{~s}$ and dark cycle for $60 \mathrm{~s}$ with an overall duration of light/dark cycles of $300 \mathrm{~s}$, data collection at $0.5 \mathrm{sec}$ interval, at $300 \mathrm{~K}$. 

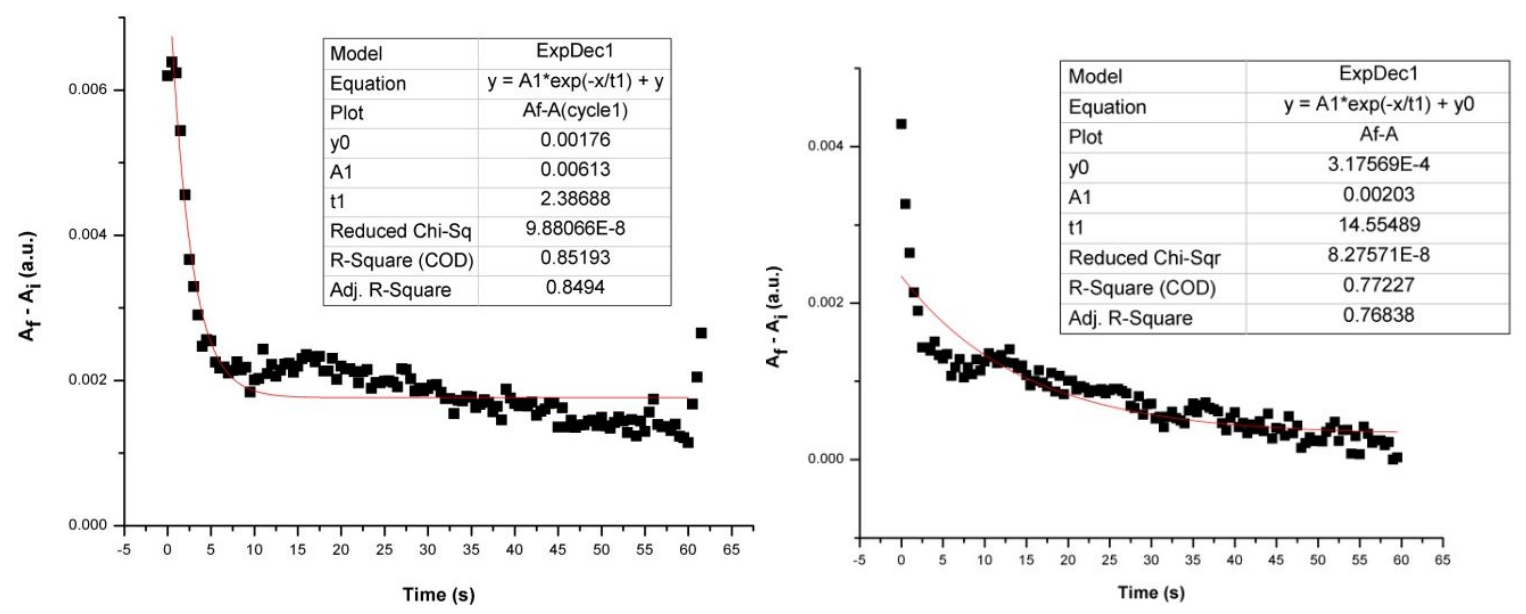

Figure S-16. First order monoexponential fit (-) of the first cycle (left), and second cycle (right). Absorbance $_{\text {final }}-$ Absorbance $_{\text {initial }}(\boldsymbol{\square})$ at $515 \mathrm{~nm}$ for SP7, upon thermal relaxation after generating a photostationary state with $100 \mathrm{~mW}$ of visible radiation. A fast and slow phase is clearly visible. 

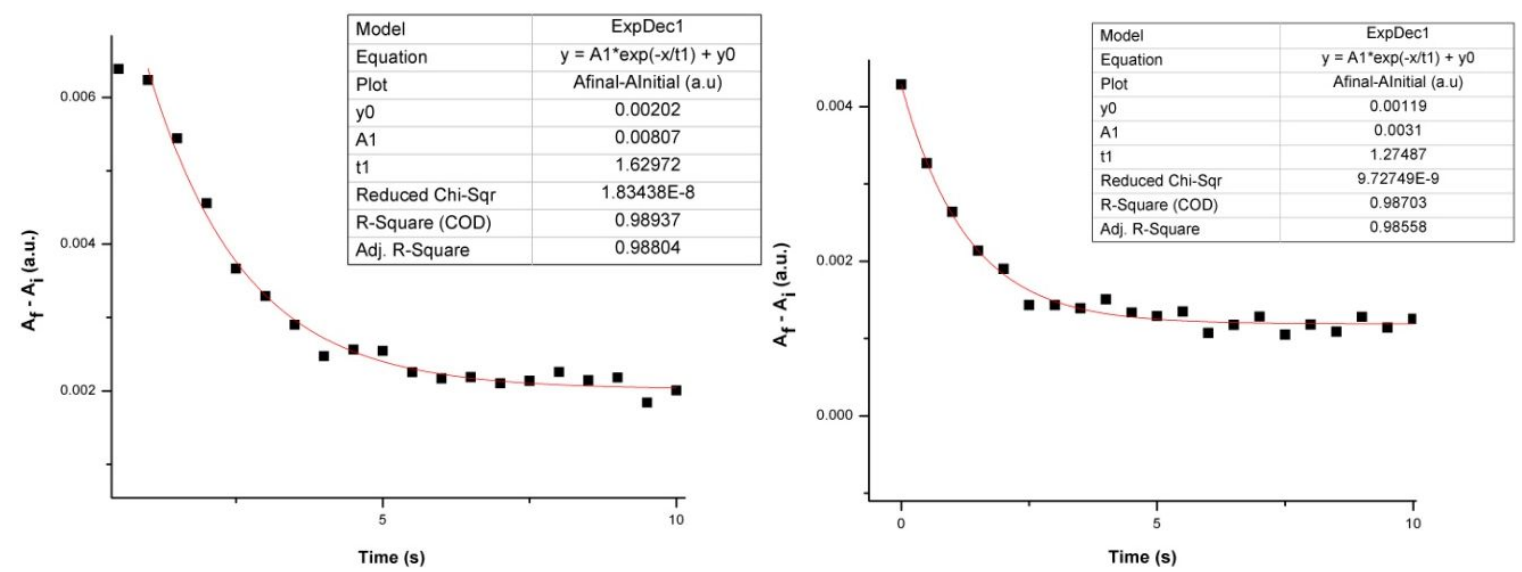

Figure S-17. Fast phase kinetics of SP7: First order monoexponential fit (-) of kinetics at early time points of both the first cycle (left), and second cycle (right). Absorbance $_{\text {final }}-$ Absorbance $_{\text {initial }}$ (a) at $515 \mathrm{~nm}$ for SP7, upon thermal relaxation after generating a photostationary state with 100 $\mathrm{mW}$ of visible radiation. Relaxation rate $k=6.14 \times 10^{-1} \mathrm{~s}^{-1}$ for cycle 1 and $k=7.84 \times 10^{-1} \mathrm{~s}^{-1}$ for cycle 2. Average $=6.99 \pm 0.02 \times 10^{-1} \mathrm{~s}^{-1}$. 

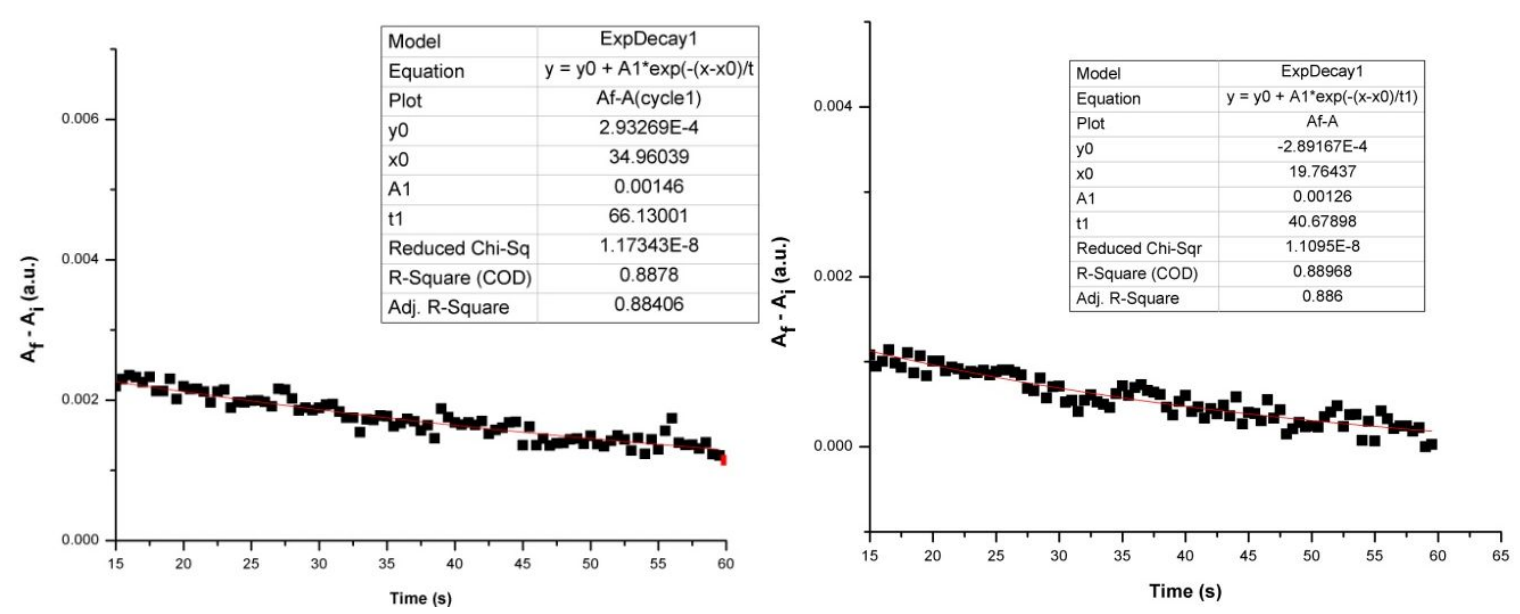

Figure S-18. Slow kinetics of SP7: First order monoexponential fit (-) of secondary kinetics of both the first cycle (left), and second cycle (right). Absorbance final $_{-}-$Absorbance $_{\text {initial }}(\mathbf{\square})$ at $515 \mathrm{~nm}$ for SP7, upon thermal relaxation after generating a photostationary state with $100 \mathrm{~mW}$ of visible irradiation. Relaxation rate $k=1.51 \times 10^{-2} \mathrm{~s}^{-1}$ for cycle 1 and $k=2.46 \times 10^{-2} \mathrm{~s}^{-1}$ for cycle 2 . Average $=1.98 \pm 0.02 \times 10^{-2} \mathrm{~s}^{-1}$. 


\section{Spiropyran 9}

For the last spiropyran, SP9, two overlapping broad peaks were observed: a shoulder at $\lambda 480 \mathrm{~nm}$ and a second absorbance at $\lambda_{\max } 600 \mathrm{~nm}$ (Fig. 14). The band at $600 \mathrm{~nm}$ is more typical of a PMC pi-pi* transition, suggesting the presence of another species in solution that may absorb at $480 \mathrm{~nm}$. Irradiation with visible light led to ring closure, as evidenced by a decrease in both the absorption bands, followed by thermal relaxation in the absence of light (Fig 15 and 16). The thermal relaxation process was followed at $480 \mathrm{~nm}$ and $600 \mathrm{~nm}$. A fit of the absorbance data at $480 \mathrm{~nm}$ gave a poor fit, suggesting that the kinetics were not first order and that absorption in this range may be due to several absorbing species. By using a biexponenial kinetics fitting, the average rate of thermal relaxations were $k_{1}=2.3 \times 10^{-2} \mathrm{~s}^{-1}$, and for $k_{2}=2.9 \pm 0.02 \times 10^{-1} \mathrm{~s}^{-1}$. The change in absorbance at $600 \mathrm{~nm}$ however was fit nicely to monoexponential kinetics (Fig 18), suggesting that the absorption is solely due to the open PMC form. The rate of thermal relaxation for SP9 was found to be $k=2.14 \times 10^{-1} \mathrm{~s}^{-1}(0.2 \mathrm{~s}-1)$, which is consistent with the thermal relaxation rates of SP3 and SP7. 

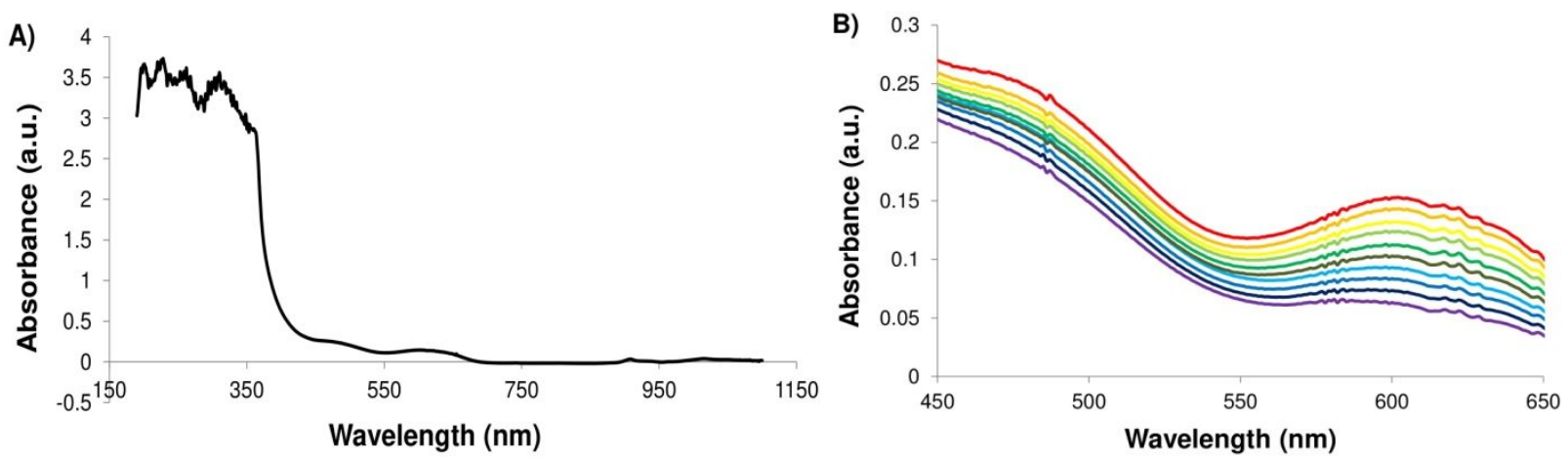

Figure S-19. (a) Electronic absorption spectrum of SP9 in ethanol $\left(8.25 \times 10^{-3} \mathrm{M}\right)$ at $300 \mathrm{~K}$ in the absence of ambient light. (b) Increase of PMC $\pi-\pi^{*}$ transition with increasing population of the PMC state due to thermal relaxation following formation of a photostationary state with visible irradiation. 


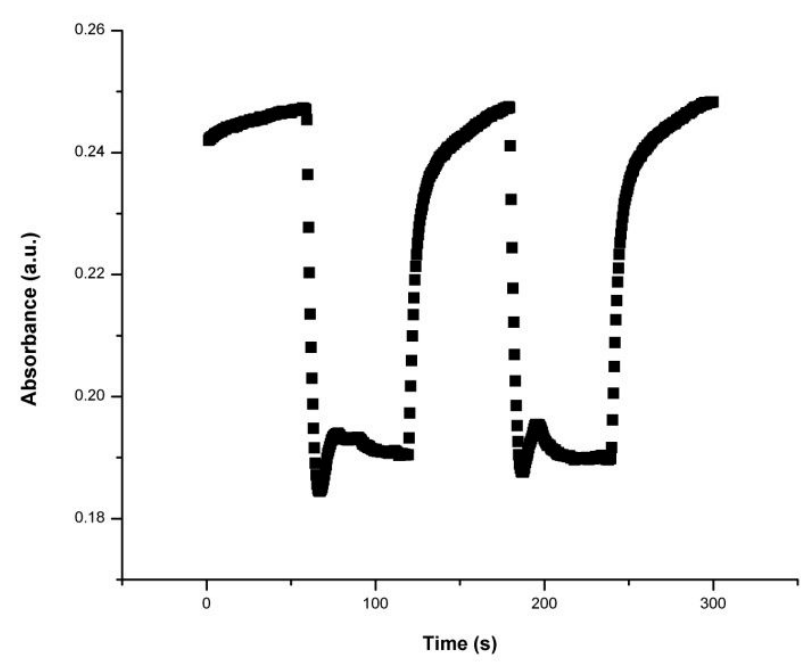

Figure S-20. Absorbance ( $\mathbf{a})$ at $480 \mathrm{~nm}$ of SP9 in ethanol $\left(8.25 \times 10^{-3} \mathrm{M}\right)$ as a function of time upon thermal relaxation/visible irradiation cycles. Light and dark cycles were carried out by thermal data collection for $60 \mathrm{~s}$, followed by excitation for $60 \mathrm{~s}$ and dark cycle for $60 \mathrm{~s}$ with an overall duration of light/dark cycles of $300 \mathrm{~s}$, data collection at $0.5 \mathrm{sec}$ interval, at $300 \mathrm{~K}$. 
Garcia et. al.

Supporting Information

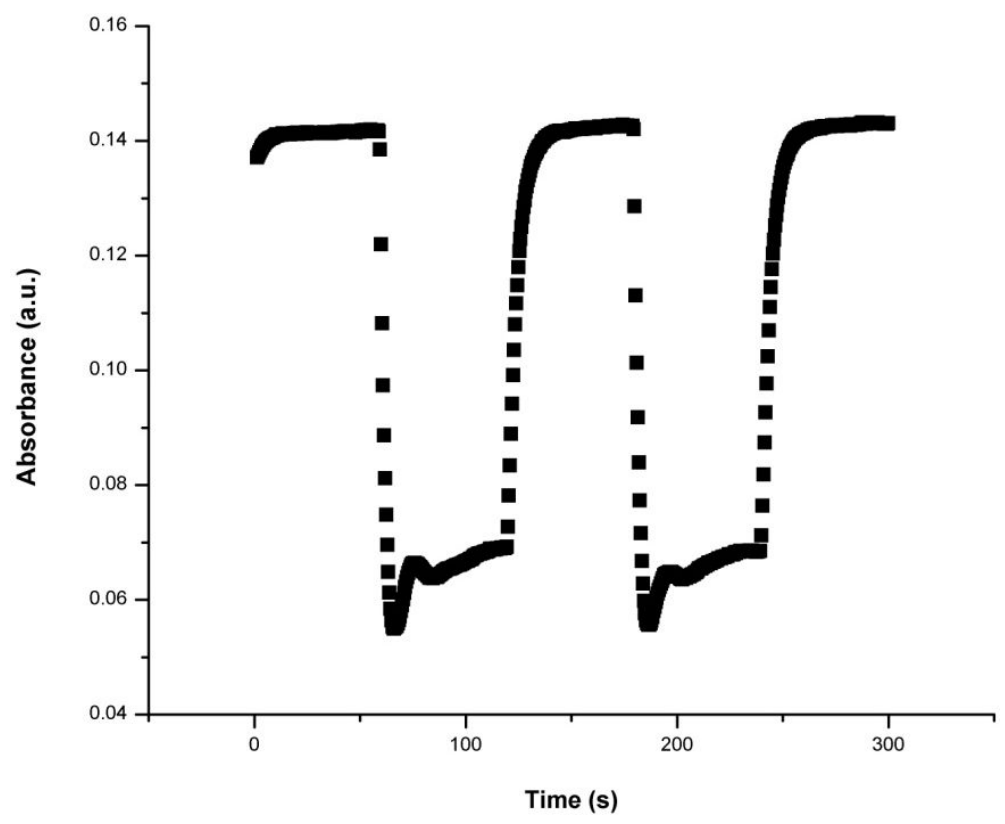

Figure S-21. Absorbance ( $\square$ ) at $620 \mathrm{~nm}$ of SP9 in ethanol $\left(8.25 \times 10^{-3} \mathrm{M}\right)$ as a function of time upon thermal relaxation/visible irradiation cycles. Light and dark cycles were carried out by thermal data collection for $60 \mathrm{~s}$, followed by excitation for $60 \mathrm{~s}$ and dark cycle for $60 \mathrm{~s}$ with an overall duration of light/dark cycles of $300 \mathrm{~s}$, data collection at $0.5 \mathrm{sec}$ interval, at $300 \mathrm{~K}$. 

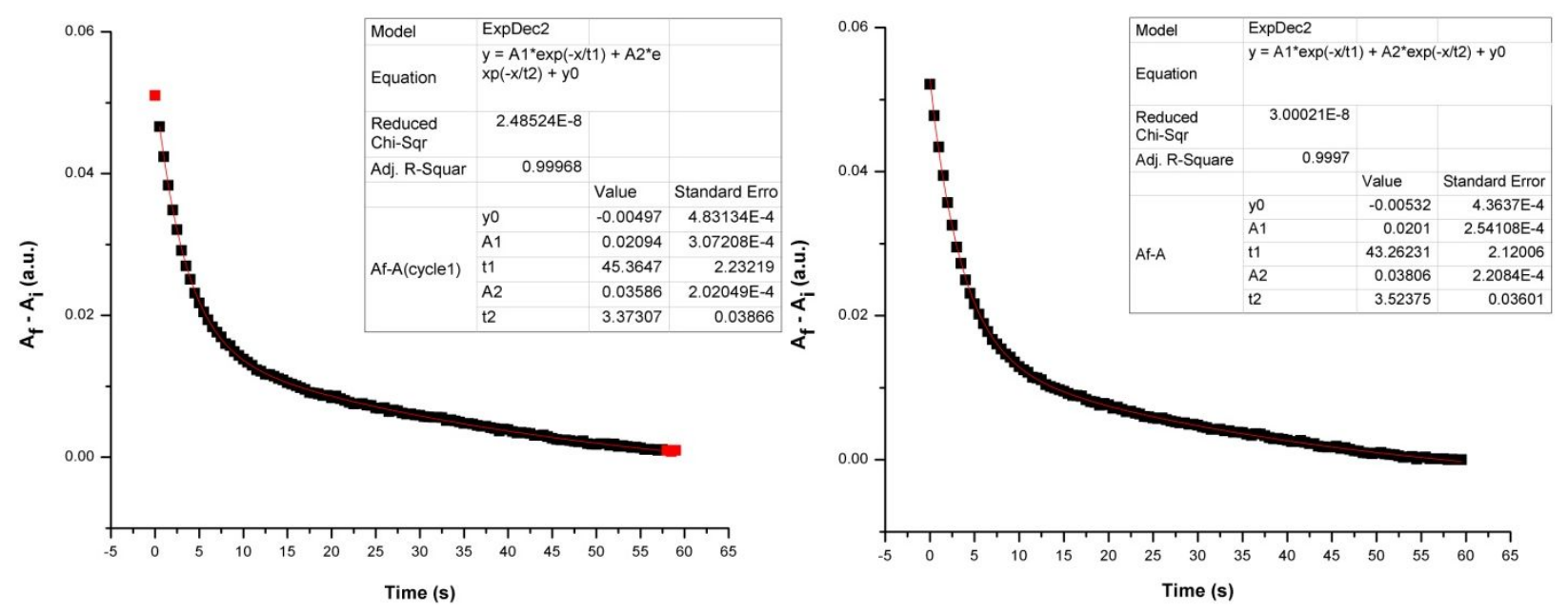

Figure S-22. First order biexponential fit (-) of the first cycle (left), and second cycle (right). Absorbance $_{\text {final }}-$ Absorbance $_{\text {initial }}(\boldsymbol{\square})$ at $480 \mathrm{~nm}$ for SP9, upon thermal relaxation after generating a photostationary state with $100 \mathrm{~mW}$ of visible irradiation. Relaxation rate $k_{1}=2.2 \times 10^{-2} \mathrm{~s}^{-1}, \mathrm{k}_{2}=$ $3.0 \times 10^{-1} \mathrm{~s}^{-1}$ for cycle 1 and $k_{1}=2.3 \times 10^{-2} \mathrm{~s}^{-1}, k_{2}=2.8 \times 10^{-1} \mathrm{~s}^{-1}$ for cycle 2 . Average rate of $k_{1}=$ $2.3 \times 10^{-2} \mathrm{~s}^{-1}$, and for $k_{2}=2.9 \times 10^{-1} \mathrm{~s}^{-1}$. 

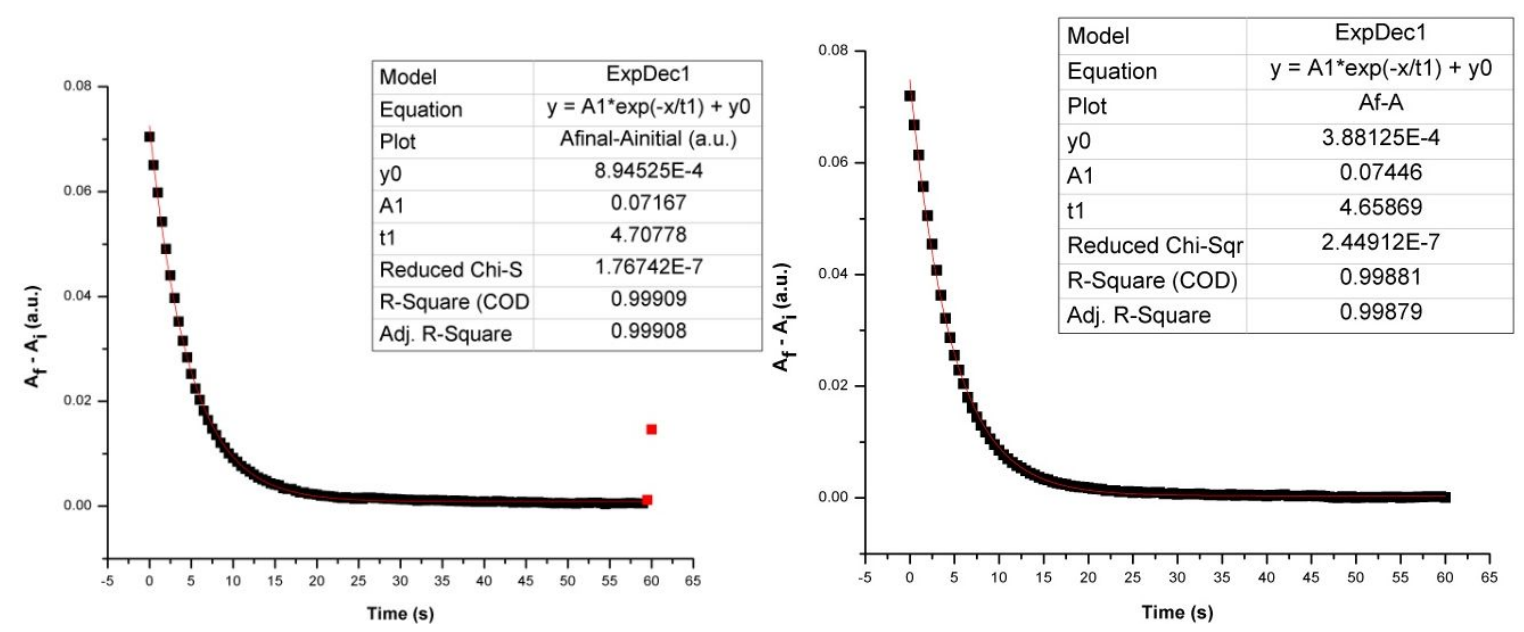

Figure S-23. First order monoexponential fit (-) of the first cycle (left), and second cycle (right). Absorbance $_{\text {final }}-$ Absorbance $_{\text {initial }}(\boldsymbol{\square})$ at $620 \mathrm{~nm}$ for SP9, upon thermal relaxation after generating a photostationary state with $100 \mathrm{~mW}$ of visible irradiation. Relaxation rate $k=2.12 \times 10^{-1} \mathrm{~s}^{-1}$ for cycle 1 and $k=2.15 \times 10^{-1} \mathrm{~s}^{-1}$ for cycle 2 . Average $=2.14 \times 10^{-1} \mathrm{~s}^{-1}$. 

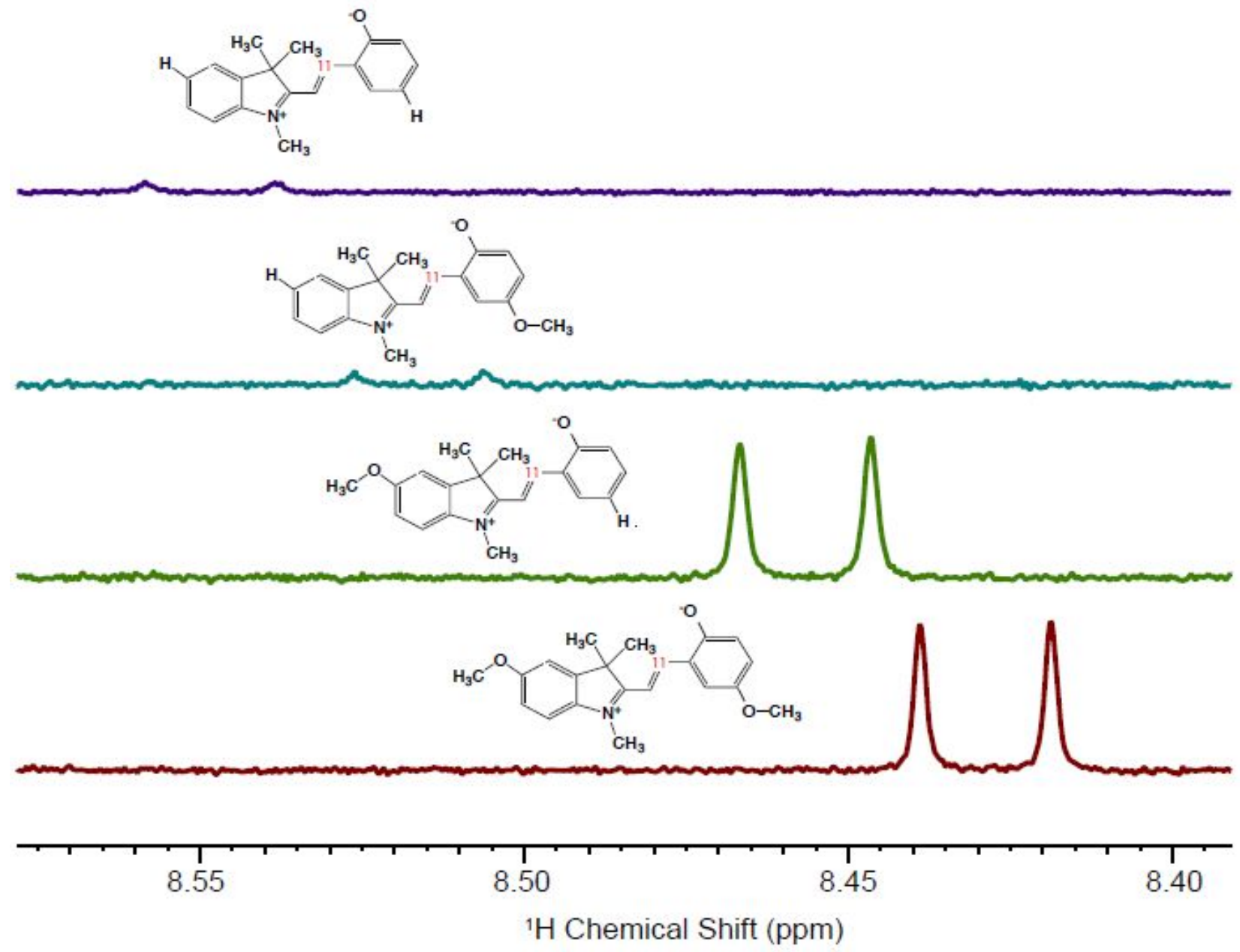

Figure S-24. ${ }^{1} \mathrm{H}$ NMR spectra of the H11 resonance from self-induced ring-open mero form for spiropyrans SP-1, 7, 3, and 9 (top to bottom). The shielding effect of the electron-donating methoxy functional groups is clear that installing methoxy groups at the 1- and 16-position of the indole and chromene fragraments drive the $\mathrm{H} 11$ resonance upfield. Additionally, the abundance of self-induced mero form increases as shielding increases. It appears then that the electron-donating effect of the methoxy group, most notably at the R1 position, influence the stability and abundance of the ring-open mero form. 


\section{References}

(1) Balmond, E. I.; Tautges, B. K.; Faulkner, A. L.; Or, V. W.; Hodur, B. M.; Shaw, J. T.; Louie, A. Y. The Journal of Organic Chemistry 2016.

(2) Shrivastava, A.; Gupta, V. B. Chronicles of Young Scientists 2011, 2, 21. 